\title{
Effects of in vitro Amitriptyline, Fluoxetine, Tranylcypromine and Venlafaxine on Saphenous Vein Grafts
}

Melek Akinci ${ }^{1}, \mathrm{MD}$; Cetin Hakan Karadag², MD; Serhat Huseyin³ ${ }^{3}$ MD; Cagatay Oltulu4, MD; Suat Canbaz ${ }^{3}$, MD; $^{4}$ Ozgur Gunduz², MD; Ruhan Deniz Topuz², MD

DOI: $10.21470 / 1678-9741-2018-0338$

\begin{abstract}
Objective: In this study, we aimed to examine the effects of amitriptyline, fluoxetine, tranylcypromine and venlafaxine on saphenous vein grafts in coronary artery bypass graft surgeries.

Methods: 59 patients (40 males and 19 females; mean age 65.1 years, distribution: $45-84$ years) who had coronary artery bypass graft surgery between February 2014 and May 2016 were included in the study. After the saphenous vein grafts with intact and denuded endothelium were precontracted with $3 \times 10^{-6} \mathrm{M}$ phenylephrine, amitriptyline, fluoxetine and tranylcypromine were cumulatively added to isolated organ baths in the range of $10^{-11}-3 \times 10^{-5} \mathrm{M}$, while venlafaxine was added in the range of $10^{-9}$. $3 \times 10^{-5} \mathrm{M}$. Then, the antidepressant-induced relaxation responses were recorded isometrically.

Results: While the relaxation response of amitriptyline at -6.42
\end{abstract}

(Log $M)$ was $74.6 \%$, the response at $-6.32(\log M)$ was $75.5 \%$. While the relaxation response at $-6.46(\log M)$ of fluoxetine was $68.02 \%$, the response at $-6.02(\log M)$ was $72.12 \%$. While the relaxation response of tranylcypromine at -7.53 ( $\log M)$ was $61.13 \%$, the response at -7.23 (Log $M)$ was $65.53 \%$. While the relaxation response of venlafaxine at -6.21 (Log $M)$ was $29.98 \%$, the response at $-5.90(\log M)$ was $32.96 \%$.

Conclusion: The maximum relaxation at minimum and maximum therapeutic concentrations was obtained with amitriptyline, fluoxetine and tranylcypromine, and the minimum relaxation was obtained with venlafaxine. The relaxation responses were independent of the endothelium.

Keywords: Saphenous Vein, Amitriptyline, Fluoxetine, Tranylcypromine, Venlafaxine.

\begin{tabular}{ll} 
Abbreviations, acronyms \& symbols \\
\hline CABG & $=$ Coronary artery bypass graft \\
NO & $=$ Nitric oxide \\
NO-cGMP & $=$ Nitric oxide-cyclic guanosine monophosphate \\
PE & $=$ Phenylephrine \\
SSRI & $=$ Selective serotonin reuptake inhibitors \\
SmPC & $=$ Summary of products characteristics \\
SV & $=$ Saphenous vein \\
\hline
\end{tabular}

\section{INTRODUCTION}

Atherosclerotic coronary artery disease is the most important cause of morbidity and mortality in industrialized countries ${ }^{[1]}$. The saphenous vein (SV) was started to be used as a graft along with the development of surgical treatment in coronary artery diseases. Although there is an increasing frequency in the use

\footnotetext{
'Deparment of Pharmacology, Faculty of Pharmacy, Trakya University, Edirne, Turkey. 2Department of Medical Pharmacology, Faculty of Medicine, Trakya University, Edirne, Turkey.

${ }^{3}$ Deparment of Cardiovascular Surgery, Faculty of Medicine, Trakya University, Edirne, Turkey.

${ }^{4}$ Deparment of Pharmaceutical Toxicology, Faculty of Pharmacy, Trakya University, Edirne, Turkey.

of arterial grafts, SV grafts are now commonly used since they provide adequate blood flow due to their wide diameters and adequate length, and for the facilities in their removal[ ${ }^{[2]}$.

Atherosclerotic coronary artery disease and major depression may exist together, and antidepressants are effective in treating the latter. In recent years, there has been an increase in the prescription of antidepressants. It was reported that $13.4 \%$ of individuals in Western countries were prescribed antidepressants at least once a year ${ }^{[3]}$. Antidepressants also have undesired and frequent side effects such as deterioration or induction of hypertension and/or leading to hypotension, affecting the cardiovascular system ${ }^{[4]}$. They produce hypotension in anesthetic agents during anesthesia, and their combinations with antidepressants may show synergy. Antidepressants may lead to undesired complications such as cardiac arrhythmia during anesthesia ${ }^{[5,6]}$ or development of treatment-resistant hypotensive episodes if used for a long time ${ }^{[7]}$. Therefore,

Correspondence Address:

Melek Akinci

(iD) https://orcid.org/0000-0003-3879-4232

Deparment of Pharmacology, Faculty of Pharmacy, Trakya University, Edirne, Turkey E-mail: melektamer@trakya.edu.tr 
clinician selection of the drug gains importance before starting the antidepressant treatment, along with cardiac and psychiatric disorders. Moreover, the hypotension-generating mechanisms of antidepressants have not been fully explained yet. Most research is considering the direct effects of antidepressants on smooth muscle cells or synaptic transmission ${ }^{[8-10]}$. However, the direct effects of antidepressants on peripheral circulation and their partial effects on the production of nitric oxide (NO), which is a strong relaxation substance, in the vein endothelium, have not been fully explained yet.

The aim of this study was to examine whether the noradrenaline reuptake inhibitor secondary amine tricyclic antidepressant amitriptyline, the monoamine oxidase irreversible inhibitor and also prostanoid synthesis inhibitor tranylcypromine, the selective serotonin reuptake inhibitor fluoxetine and the serotonin-noradrenaline reuptake inhibitor venlafaxine had direct effects on vein in in vitro SV grafts used in coronary artery bypass graft (CABG) surgeries.

\section{METHODS}

The SV graft materials received from patients who were hospitalized in Cardiovascular Surgery Clinic and who had coronary artery bypass surgery were used in the study. The ethics committee approval was obtained before the study (Ethical Committee Number:TUTF-GOKAEK 2012/201). Fifty-nine patients who had CABG surgery between February 2014 and May 2016 were included in the study. Patients were informed about the operations to be performed and the informed consent forms were obtained. A part of approximately $1 \mathrm{~cm}$, which remained in the preparation stage of SV as a graft, was taken into a Petri dish containing $+4^{\circ} \mathrm{C}$ Krebs solution without undergoing any procedure and was brought to the Department of Medical Pharmacology in the Faculty of Medicine. The composition of Krebs solution (mM) was as follows: $\mathrm{NaCl} 122, \mathrm{KCl} 5, \mathrm{CaCl}_{2} 1.25$, $\mathrm{NaHCO}_{3}$ 25.0, $\mathrm{MgSO}_{4}$ 1.2, $\mathrm{KH}_{2} \mathrm{PO}_{4}$ 1, glucose 11.5. The SV graft was decontaminated from peripheral tissues at $22^{\circ} \mathrm{C}$ at room temperature, and $2 \mathrm{~mm}$ long ring-shaped specimens were cut and suspended horizontally between a platinum hanger connected to the isometric transducer (FDT 05, COMMAT, Turkey) and a platinum hook in the organ bath deaerated with carbogen $\left(95 \% \mathrm{O}_{2}+5 \% \mathrm{CO}_{2}\right)$ at $37^{\circ} \mathrm{C}$ and containing $10 \mathrm{~mL}$ of Krebs solution. The precontraction was determined as 2 grams. The responses were transferred to the electronic environment by means of Transducer Acquisition System (COMMAT FDT 5,
COMMAT Ltd., Ankara, Turkey) and recorded in BIOPAC BSL 4.0 MP 36 program.

For adaptation to the environment, flushing was made every 15 minutes for 1 hour. The precontraction was brought to 2 grams. To test the presence of vein endothelium, it was tested whether or not there was a relaxation response by adding $10^{-}$ ${ }^{6} \mathrm{M}$ acetylcholine to tissues that were contracted submaximally with $3 \times 10^{-6} \mathrm{M}$ phenylephrine (PE). The tissues that did not show adequate relaxation response were excluded from study. The absence of the endothelial layer was evaluated as a decrease of $80 \%$ or more in the relaxation response induced to ACh $(1 \mu \mathrm{M})$.

In our study, the effects of antidepressants on precontraction by PE were examined in tissues with intact endothelium and mechanically damaged endothelium. The vein endothelium was damaged by turning right and left for 10 times with the help of a rough stainless steel bar which was introduced into the lumen. The precontraction was induced in tissues with $3 \times 10^{-6} \mathrm{M} \mathrm{PE}$. Amitriptyline, tranylcypromine and fluoxetine were cumulatively added in the concentration range of $10^{-11}-3 \times 10^{-5} \mathrm{M}$, and venlafaxine was applied in the concentration range of $10^{-9}-3 \times 10^{-5} \mathrm{M}$ when the distention reached the plate following the precontraction.

In our study, the logarithm of the molar concentration corresponding to the therapeutic plasma concentrations of amitriptyline, fluoxetine, tranylcypromine and venlafaxine was calculated (Table 1). For clinical significance, the relaxation responses (\%) of the drugs corresponding to the therapeutic lower and upper plasma concentrations were compared.

\section{Drugs}

$\mathrm{NaCl}$ (Sigma), $\mathrm{KCl}$ (Sigma), $\mathrm{CaCl}_{2}$ (Sigma), $\mathrm{NaHCO}_{3}$ (Sigma), $\mathrm{MgSO}_{4}$ (Sigma), $\mathrm{KH}_{2} \mathrm{PO}_{4}$ (Sigma), glucose (Sigma), acetylcholine (Sigma), phenylephrine (Sigma), amitriptyline (Sigma), fluoxetine (Sigma), tranylcypromine (Sigma), venlafaxine (Tocris). All drugs were dissolved in distilled water.

\section{Statistical Analysis}

The concentration-response graphics (\%) of relaxation of tissues with intact endothelium and mechanically damaged endothelium at therapeutic blood concentrations were obtained with the Graphpad Prism 6.01 Demo program and one-way variance analysis (One-way ANOVA). Then, the Bonferroni post hoc test was applied to the data. The results with $P$ values below $0.05(P<0.05)$ were considered statistically significant (Table 1$)$.

Table 1. Drug names, therapeutic plasma concentrations (lower limit-upper limit), molar concentration values and -logarithm values corresponding to molar concentration values.

\begin{tabular}{l|c|c|c}
\hline \multicolumn{1}{c|}{ Drug names } & $\begin{array}{c}\text { Therapeutic plasma concentrations (ng/mL) } \\
\text { (lower limit-upper limit) }\end{array}$ & $\begin{array}{c}\text { Molar concentration values (M) } \\
\text { (lower limit-upper limit) }\end{array}$ & $\begin{array}{c}\text { Logarithm values (Log M) } \\
\text { (lower limit-upper limit) }\end{array}$ \\
\hline Amitriptyline & $120-150$ & $3.82 \times 10^{-7}-4.78 \times 10^{-7}$ & $(6.42)-(6.32)$ \\
\hline Fluoxetine & $120-300$ & $3.47 \times 10^{-7}-8.68 \times 10^{-7}$ & $(6.46)-(6.06)$ \\
\hline Tranylcypromine & $05-10$ & $2.98 \times 10^{-8}-5.9 \times 10^{-8}$ & $(7.53)-(7.23)$ \\
\hline Venlafaxine & $195-400$ & $6.21 \times 10^{-7}-1.27 \times 10^{-6}$ & $(6.21)-(5.90)$ \\
\hline
\end{tabular}




\section{RESULTS}

PE was added cumulatively to the SV grafts with intact endothelium and with mechanically damaged endothelium in the concentration range of $10^{-8}-3 \times 10^{-5} \mathrm{M}$, and the concentrationcontraction (\%) graphics belonging to PE were obtained.

Pre-contraction was induced in the tissues with $3 \times 10^{-6} \mathrm{M}$ PE in isolated human SV grafts with intact endothelium and with mechanically damaged endothelium. Cumulative concentrations of antidepressants were added to the tissues when the distention reached the plate following precontraction. Amitriptyline, tranylcypromine and fluoxetine were applied in the concentration range of $10^{-11}-3 \times 10^{-5} \mathrm{M}$, while venlafaxine was applied in the concentration of $10^{-9}-3 \times 10^{-5} \mathrm{M}$ (Figure 1).

Relaxation responses of amitriptyline in isolated human SV grafts precontracted with submaximal PE and intact endothelium and with mechanically damaged endothelium

The relaxation responses were induced depending on the concentration of amitriptyline applied in the isolated human SV grafts with $3 \times 10^{-6} \mathrm{M}$ PE following precontraction. Amitriptyline induced relaxation at a rate of $94.6 \%$ in SV grafts with intact endothelium, while inducing the maximum relaxation at a rate of $116.6 \%$ in grafts with mechanically damaged endothelium. While the relaxation response at $-6.42(\log M)$, the lower limit of therapeutic dose range belonging to amitriptyline in humans, was $74.6 \%$, the response at $-6.32(\log M)$, the upper limit, was $75.5 \%$. The concentration-relaxation (\%) graphs obtained with amitriptyline in the concentration range of $10^{-11}-3 \times 10^{-5} \mathrm{M}$ in isolated human SV grafts with intact endothelium and with mechanically damaged endothelium are shown in Figure 2 . The lower and upper therapeutic limits of relaxation of amitriptyline in SV grafts with intact endothelium and with mechanically damaged endothelium were statistically significant compared to venlafaxine $(P<0.0001)$.

Relaxation responses of fluoxetine in isolated human SV grafts precontracted with submaximal PE and intact endothelium and with mechanically damaged endothelium

The relaxation responses were induced depending on the concentration of fluoxetine applied in the isolated human SV
A

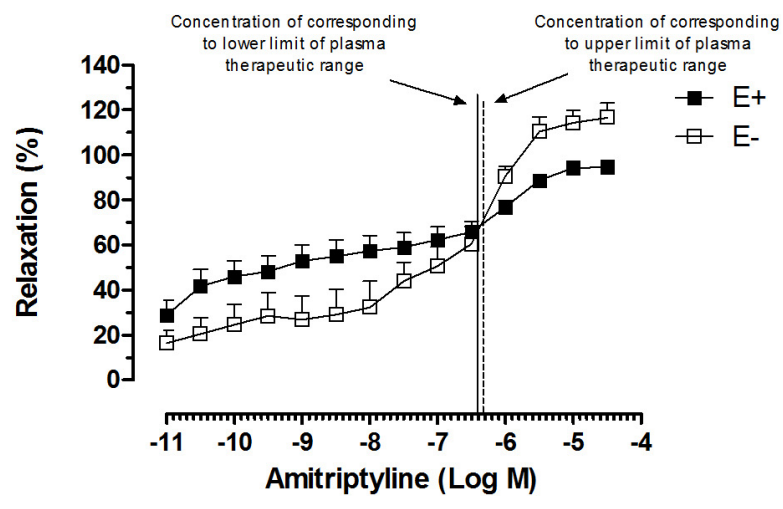

C

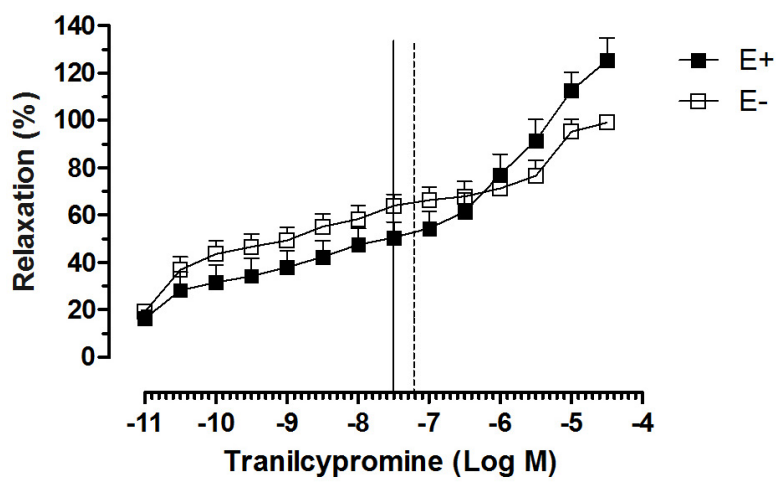

B

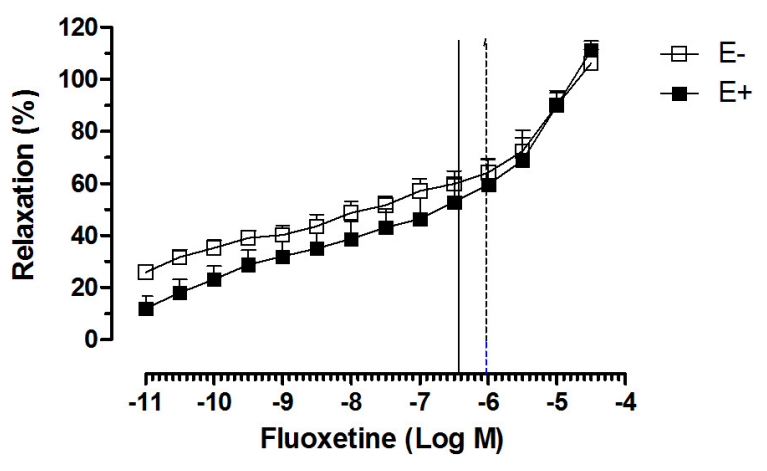

D

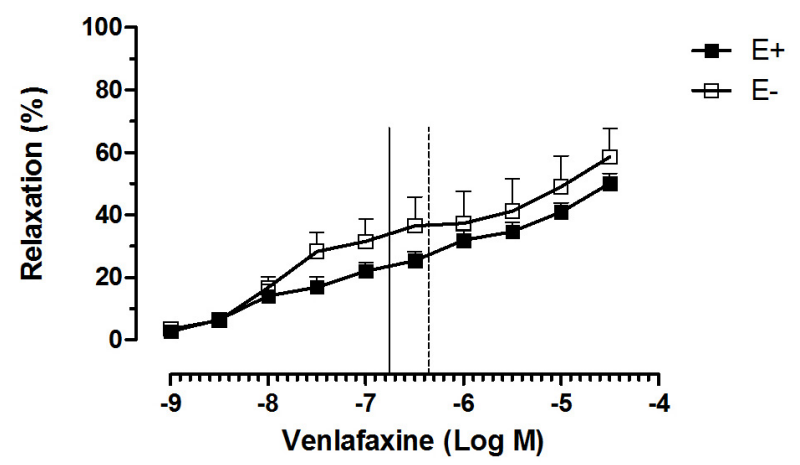

Fig. 1 - Graph of concentration-relaxation (\%) induced by amitriptyline (A), fluoxetine (B), tranylcypromine (C) and venlafaxine (D) added cumulatively to isolated human saphenous vein grafts with endothelium precontracted with submaximal phenylephrine $\left(3 \times 10^{-6} \mathrm{M}\right)(E+)$ and mechanically damaged endothelium ( $E-$ ) ( $n=8$ for each drug).

The vertical line in the graph represents the lower limit of therapeutic plasma concentrations of these drugs in humans. The dotted vertical line in the graph represents the upper limit of the therapeutic plasma concentrations of these drugs. 
grafts with $3 \times 10^{-6} \mathrm{M}$ PE following precontraction. Fluoxetine induced relaxation at a rate of $111.2 \%$ in SV grafts in which the endothelium was intact while inducing the maximum relaxation in the ratio of $106.2 \%$ in the grafts with intact endothelium and with mechanically damaged endothelium. While the relaxation response at $-6.46(\log M)$, the lower limit of therapeutic dose range belonging to fluoxetine in humans, was $68.02 \%$, the response at $-6.02(\log M)$, the upper limit, was $72.12 \%$. The concentration-relaxation (\%) graphs obtained with fluoxetine in the concentration range of $10^{-11}-3 \times 10^{-5} \mathrm{M}$ in isolated human SV grafts with intact endothelium and with mechanically damaged endothelium are shown in Figure 2. The lower and upper therapeutic limits of relaxation of fluoxetine in SV grafts with intact endothelium were statistically significant compared to venlafaxine $(P<0.0001)$. The therapeutic lower and upper limits of relaxation of fluoxetine in SV grafts with mechanically damaged endothelium were statistically significant compared to venlafaxine $(P<0.0001)$.

Relaxation responses of tranylcypromine in isolated human SV grafts precontracted with submaximal PE and intact endothelium and with mechanically damaged endothelium

The relaxation responses were induced depending on the concentration of tranylcypromine applied in the isolated human SV grafts with $3 \times 10^{-6} \mathrm{M}$ PE following precontraction. Tranylcypromine induced relaxation at a rate of $125.3 \%$ in SV grafts with intact endothelium, while inducing the maximum relaxation at a rate of $99.08 \%$ in the grafts with mechanically damaged endothelium. While the relaxation response at -7.53 $(\log M)$, the lower limit of therapeutic dose range belonging to tranylcypromine in humans, was $61.13 \%$, the response at -7.23 (Log M), the upper limit, was $65.53 \%$. The concentrationrelaxation (\%) graphs obtained with tranylcypromine in the concentration range of $10^{-11}-3 \times 10^{-5} \mathrm{M}$ in isolated human SV grafts with intact endothelium and with mechanically damaged endothelium are shown in Figure 2. The lower and upper therapeutic limits of relaxation of tranylcypromine in SV grafts with intact endothelium were statistically significant compared to venlafaxine $(P<0.0001)$. The lower and upper therapeutic limits of relaxation of tranylcypromine in SV grafts with mechanically damaged endothelium were statistically significant compared to venlafaxine $(P<0.0001)$.

Relaxation responses of venlafaxine in isolated human SV grafts precontracted with submaximal PE and intact endothelium and with mechanically damaged endothelium

The relaxation responses were induced depending on the concentration of venlafaxine applied in the isolated human SV grafts with $3 \times 10^{-6} \mathrm{M} P E$ following precontraction. Venlafaxine induced relaxation at a rate of $50.02 \%$ in SV grafts with intact endothelium, while inducing the maximum relaxation at a rate of $58.52 \%$ in grafts with mechanically damaged endothelium. While the relaxation response at -6.21 (Log M), the lower limit of therapeutic dose range belonging to venlafaxine in humans, was $29.88 \%$, the response at $-5.90(\log M)$, the upper limit, was $32.96 \%$. The concentration-relaxation (\%) graphs obtained with venlafaxine in the concentration range of $10^{-9}-3 \times 10^{-5} \mathrm{M}$ in isolated human SV grafts with intact endothelium and with mechanically damaged endothelium are shown in Figure 2. Amitriptyline, fluoxetine and tranylcypromine were statistically
A The relaxation induced minimum-maximum therapeutic concentration $(E+)$

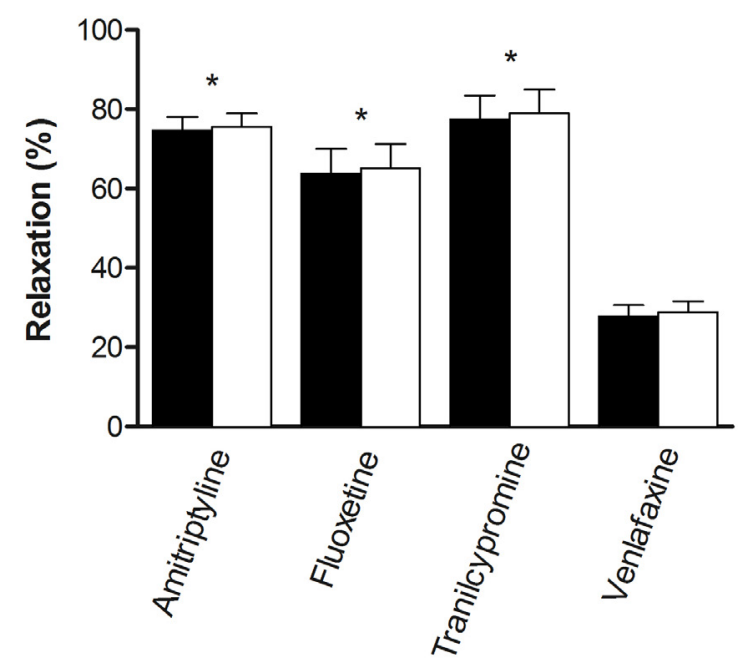

B The relaxation induced minimum-maximum therapeutic concentration (E-)

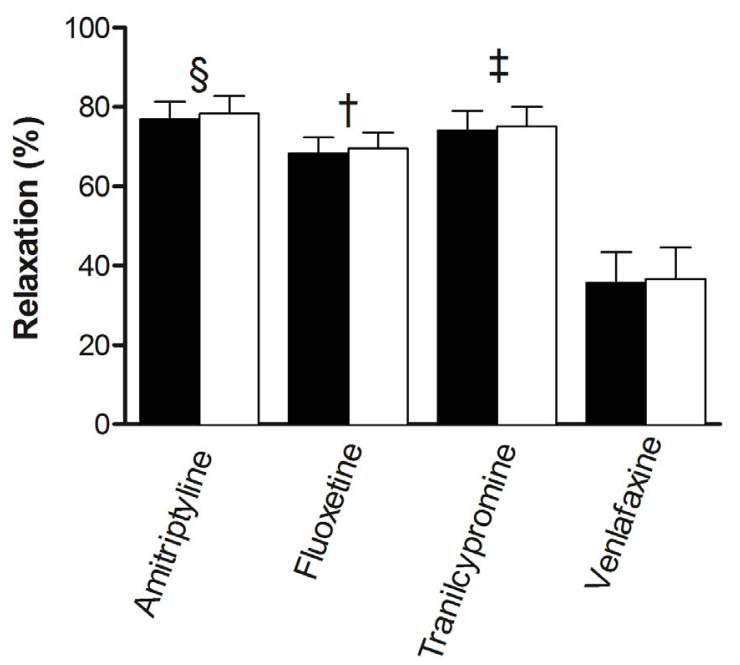

Fig. 2 - Statistical comparison of relaxations (\%) at minimum (black) and maximum (white) therapeutic plasma concentrations of amitriptyline, fluoxetine, tranylcypromine and venlafaxine in isolated human saphenous vein grafts with (A) Endothelium intact precontracted with submaximal phenylephrine $\left(3 \times 10^{-6} \mathrm{M}\right)$ and $(B)$ Endothelium denuded ( $n=8$ for each drug).

*: $P<0.05,+: P<0.01, \neq: P<0.001, \S: P<0.0001$, vs. venlafaxine. 
significant compared to venlafaxine in terms of minimum and maximum therapeutic concentrations in the isolated human SV grafts precontracted with submaximal PE and with intact endothelium $(P<0.0001)$.

\section{DISCUSSION}

In our study, we aimed to examine the vasoactive effects of antidepressants on human isolated SV graft smooth muscle. In this study, isolated human SV grafts precontracted with PE and intact endothelium and with mechanically damaged endothelium were relaxed by various types of antidepressants depending on the concentration. Amitriptyline, fluoxetine and tranylcypromine displayed vasorelaxant properties at minimum and maximum therapeutic concentrations in isolated human SV grafts with intact endothelium and with mechanically damaged endothelium, and venlafaxine induced minimum relaxation. The responses were independent of the endothelium.

In their study, Ribbacketal. ${ }^{[1]}$ demonstrated that antidepressants mainly had vasodilation effects on isometric contraction. They reported that the pharmacomechanical and electromechanical mechanisms in smooth muscle cells played a role in this effect, and incubation with antidepressant agents in low concentrations inhibited the contractile adrenergic responses related to nitric oxide-cyclic guanosine monophosphate (NO-cGMP) pathway.

Amitriptyline is a tricyclic antidepressant agent which is a postsynaptic cholinergic receptor antagonist in smooth muscle cells in vitro. In our study, amitriptyline relaxed SV grafts with adrenergic elicited tension following the contraction, and its $a_{1}$ antagonistic property was proved in this way. Our findings were consistent with findings from previous studies ${ }^{[8,9,11-13]}$. Moreover, we demonstrated that amitriptyline relaxed the isolated human SV graft independently of the endothelium. In a clinical study on the determination of placebo and baseline-controlled side effects of amitriptyline, the amitriptyline group reported a high level of side effects, depending on xerostomia, dizziness and subjective blood circulation ${ }^{[14]}$. Side effects, depending on the blood circulation disorder, were consistent with our findings. It should be taken into consideration that in our study amitriptyline relaxed the isolated human SV grafts depending on the dose, and therefore, blood pressure can be reduced indirectly and may lead to dizziness in humans. Our study is consistent with the results of clinical studies conducted on amitriptyline.

In a study conducted by Pereira et al. ${ }^{[15]}$, chronic fluoxetine (10 mg/kg/day) was applied to Wistar rats for 21 days. Chronic treatment with fluoxetine has been shown to decrease PEinduced vasocontraction, but had no effect on vasoconstriction induced by electrical field stimulation. The chronic treatment with fluoxetine regulates vascular sympathetic adrenergic responses by affecting the presynaptic mechanisms and prevents the reuptake of noradrenaline. Thus, it increases the noradrenaline in the synaptic range. This leads to a decrease in vasoconstriction, peripheral vascular resistance and orthostatic hypotension ${ }^{[15]}$. Similar to the study by Pereira et al., fluoxetine has been shown to reduce $\mathrm{PE}$-induced vasoconstriction. Orthostatic hypotension may occur as a result of decreased peripheral vascular resistance. In a study conducted by Ungvari et al. ${ }^{[16]}$ in rat brain arterioles, they demonstrated that the relaxation effects of fluoxetine were not dependent on the endothelium. In our study, fluoxetine decreased precontraction induced by $\mathrm{PE}$, which is an adrenergic agonist, in isolated human SV grafts in a dose-dependent manner. In our study, fluoxetine-dependent relaxation responses were independent of the endothelium, similar to the study of Ungvari et al. ${ }^{[16]}$ On the other hand, Ribback et al. ${ }^{[1]]}$ demonstrated in their study in rat aorta that the vasoconstrictor responses to adrenergic stimuli partially inhibited fluoxetine in low concentrations in an endotheliumdependent manner. Moreover, inhibition of NO or cGMP production resulted in the decrease of medicine-preparation sensitivity against fluoxetine. In this way, it was demonstrated that NO-cGMP pathway in rat aorta was significant in the relaxation mechanism of fluoxetine ${ }^{[11]}$. In our study, the relaxation responses induced by fluoxetine were independent of the endothelium. The reason why the results of our study were different from that of Ribback et al. ${ }^{[11]}$ may be due to them using isolated rat aorta in their study.

There are not enough studies conducted on the effect of tranylcypromine on veins in the literature. In a study conducted by Ribback et al.. ${ }^{[1]}$, tranylcypromine induced relaxation in rat aorta precontracted with PE in a dose-dependent manner. There was no statistically significant difference between tissues with intact endothelium and with damaged endothelium in terms of relaxation responses. In our study, tranylcypromine relaxed the isolated human SV grafts precontracted with PE in a dose-dependent manner. Moreover, there was no statistically significant difference between SV grafts tissues with intact endothelium and with mechanically damaged endothelium. Therefore, the results of our study are consistent with the results of Ribback et al. ${ }^{[11]}$ Moreover, 105 psychiatric drugs used in adult psychiatry in Germany were compared with risks of causing arterial hypertension or hypotension, and it was reported in the Summary of Products Characteristics (SmPC) that amitriptyline and tranylcypromine had lower contraction risks compared with the other drugs. Venlafaxine and tranylcypromine, by contrast, had a reverse effect, specifically with some diets ${ }^{[17]}$. In our study, it has been shown that amitriptyline and tranylcypromine may have a low risk of low blood pressure in SMPC since they relax the isolated human SV grafts in a dose-dependent manner. Moreover, tranylcypromine has a relation with arachidonic acid oscillation, which is a precursor of all prostanoids, and inhibits the synthesis of prostacyclin. Some vascular side effects of tranylcypromine occur along with the release of prostanoid homeostasis ${ }^{[18]}$. In our study, the effect of prostanoids on relaxation responses of tranylcypromine has not been studied. Therefore, prostanoids may be planned in further studies to identify components that demonstrate the vascular effects of tranylcypromine.

Bujak-Gizycka et al. ${ }^{[19]}$ revealed a proangiotensin-12 creating skill which induced substrate for renin-independent angiotensinogen I-II formation from rat aorta. Angiotensinogen II blood pressure plays a critical role in the local hemostasis regulation. It can be researched whether a proangiotensin-12like substance determined in rat aorta exists in humans or not. Moreover, further researches can be planned on the effects of antidepressants that are known to have vasoactive properties in the renin-angiotensinogen system.

Venlafaxine has selective serotonergic side effects with selective serotonin reuptake inhibitors (SSRI). Additionally, it 
leads to noradrenergic side effects, specifically stimulation of cardiovascular disorders. At the end of many meta-analyses of more than 70 published and unpublished randomized clinical trials, to which 7000 patients in total were included, it was demonstrated that discontinuation of treatment depending on side effects was much more common in venlafaxine compared to SSRI antidepressants. Moreover, exposure to venlafaxine has been reported to increase pre-eclampsia and eclampsia in the second and third trimesters of pregnancy. Data obtained from clinical and epidemiological studies conducted from mid-2015 confirm that venlafaxine has higher cardiovascular side effects and fatal risk of overdose compared to SSRI antidepressants ${ }^{[20]}$. It was reported that venlafaxine induced or deteriorated hypertension ${ }^{[21]}$. Venlafaxine causes noradrenaline, serotonin and dopamine release in the central nervous system ${ }^{[22]}$. Moreover, it was demonstrated that venlafaxine increased the vasoconstriction induced by noradrenaline in human dorsal hand vein ${ }^{[23]}$. On the other hand, pulmonary hypertension risk was low in isolated perfused rat lungs even at low concentrations ${ }^{[24]}$. In contrast, the fact that the risk of causing pulmonary hypertension in isolated perfused rat lungs was low even in high concentrations is consistent with our study results. In the study by Ribback et al. ${ }^{[1]}$ in rat aorta, it was demonstrated that venlafaxine did not lead to relaxation, but it caused contraction in aorta preparations with intact endothelium. In our study, venlafaxine relaxed the isolated human saphenous vein grafts precontracted with PE and with intact endothelium and with mechanically damaged endothelium in a dose-dependent manner. However, the relaxation induced by venlafaxine was statistically significant compared with other antidepressant drugs. In contrast to the aforementioned studies ${ }^{[11,20,21,23]}$, venlafaxine has relaxed isolated human SV grafts with intact endothelium precontracted with PE $(E+)$ and with mechanically damaged endothelium (E-) in a dose-dependent manner. However, the relaxation induced by venlafaxine was significantly lower than the other antidepressant drugs we tested. This difference may be due to the fact that we used isolated SV graft in our study.

Additionally, it was reported that there was a strong and statistically significant correlation between antidepressant use and long-term survival in patients undergoing nonemergency CABG surgery in Sweden over a three-year period between 2006 and 2008. Moreover, use of antidepressants was correlated with coronary failure, myocardial infarction, cerebrovascular accident and risk of death or rehospitalization ${ }^{[25]}$.

As a limitation of this study, it should be taken into consideration in the evaluation of the results that individual differences can be observed in people's responses to medications.

\section{CONCLUSION}

Our study supports the hypothesis that the antidepressantinduced side effects on blood pressure have direct effects on blood vessels, at least to some degree. Amitriptyline, fluoxetine and tranylcypromine displayed vasorelaxant properties. Venlafaxine induced less relaxation compared to other antidepressants. If patients who had CABG surgery have to take antidepressants, it can be suggested that the antidepressant which had the least hypotensive effect in the early period can be used at the minimum effective dose. Based on the results of our study, the antidepressant with this effect was venlafaxine. Besides that, discontinuation of antidepressants prior to anesthesia can be decided by considering the differences between the vein level relaxation effects among antidepressants. Moreover, it should be taken into consideration at the time of drug selection that selective serotonin reuptake inhibitors such as fluoxetine may lead to perioperative or postoperative bleeding in patients undergoing CABG surgery. It should be proved that antidepressant agents acting on the veins are responsible for blood pressure in a similar way.

Presented Congress: Association of Thrace of Universities $1^{\text {st }}$ International Health Sciences Congress, 23-25 November 2017, Edirne/Turkey.

Financial Support: Research Fund of Trakya University x Project Number: 2013/34.

\section{No conflict of interest.}

\section{Authors' roles \& responsibilities}

MA Substantial contributions to the conception or design of the study; or the acquisition, analysis, or interpretation of data for the study; final approval of the version to be published

CHK Substantial contributions to the conception or design of the study; or the acquisition, analysis, or interpretation of data for the study; final approval of the version to be published

SH Substantial contributions to the conception or design of the study; or the acquisition, analysis, or interpretation of data for the study; final approval of the version to be published

CO Substantial contributions to the conception or design of the study; or the acquisition, analysis, or interpretation of data for the study; final approval of the version to be published

SC Substantial contributions to the conception or design of the study; or the acquisition, analysis, or interpretation of data for the study; final approval of the version to be published

OG Substantial contributions to the conception or design of the study; or the acquisition, analysis, or interpretation of data for the study; final approval of the version to be published

RDT Substantial contributions to the conception or design of the study; or the acquisition, analysis, or interpretation of data for the study; final approval of the version to be published

\section{REFERENCES}

1. Raja SG, Haider Z, Ahmad M, Zaman H. Saphenous vein grafts: to use or not to use? Heart Lung Circ. 2004;13(4):403-9. doi:10.1016/j. hlc.2004.04.004.

2. Us MH, Inan K, Caglı K, Cingozboy Y, Yıldırım S, Duran E, Ozturk OY ve ark. Safen ven gretfi hazırlanmasında Endotelin Nitroprussid ile korunması. Türk Göğüs Kalp Damar Cerrahi dergisi 2001; 9:105-8. Turkish. 
3. Rheker J, Winkler A, Doering BK, Rief W. Learning to experience side effects after antidepressant intake-results from a randomized, controlled, double-blind study. Psychopharmacology. 2017;234(3):32938. doi:10.1007/s00213-016-4466-8.

4. Pacher P, Ungvari Z, Kecskemeti V, Furst S. Review of cardiovascular effects of fluoxetine, a selective serotonin reuptake inhibitor, compared to tricyclic antidepressants. Curr Med Chem. 1998;5(5):381-90. doi:10.1002/chin.199901317.

5. Edwards RP, Miller RD, Roizen MF, et al. Cardiac responses to imipramine and pancuronium during anesthesia with halothane or enflurane. Anesthesiology. 1979;50(5):421-5. doi:10.1097/00132586-198004000-00029.

6. Glisson SN, Fajardo L, El-Etr AA. Amitriptyline therapy increases electrocardiographic changes during reversal of neuromuscular blockade. Anesth Analg 1978;57(1):77-83. doi:10.1213/00000539197801000-00013.

7. Sprung J, Schoenwald PK, Levy P, Krajewski LP. Treating intraoperative hypotension in a patient on long-term tricyclic antidepressants: a case of aborted aortic surgery. Anesthesiology [Internet]. 1997 [cited 2019 Apr 27];86(4):990-2. Available from: https://www.ncbi.nlm.nih. gov/pubmed/9105244.

8. Huang Y. Inhibition of contractions by tricyclic antidepressants and xylamine in rat vas deferens. Eur J Pharmacol. 1997;327(1):41-7.

9. Huang $Y$, Lau CW. Inhibitory effect of amitriptyline on contraction of the rat isolated trachea. Pharmacology. 1997;54(6):312-8. doi:10.1159/000139501.

10. Velasco A, Arruza A, Maroto M, Carvajal A, Fernandez del Busto E, Garcia del Pozo J. Effect of venlafaxine hydrochloride in different preparations of isolated guinea-pig and rat organ tissues. J Auton Pharmacol. 1999;19(2):109-13. doi:10.1046/j.1365-2680.1999.00124.x.

11. Ribback S, Pavlovic D, Herbst D, Nedeljkov-Jancic R, Wendt M, Nedeljkov V,et al. Effects of amitriptyline, fluoxetine, tranylcypromine and venlafaxine on rat vascular smooth muscle in vitro--the role of the endothelium. J Physiol Pharmacol [Internet]. 2012 [cited 2019 Apr 27];63(2):119-25. Available from: https://www.ncbi.nlm.nih.gov/ pubmed/22653897.

12. Kalkan S, Aygoren O, Akgun A, Gidener S, Guven H, Tuncok Y. Do adenosine receptors play a role in amitriptyline-induced cardiovascular toxicity in rats? J Toxicol Clin Toxicol. 2004;42(7):945-54. doi:10.1081/ CLT-200041845.

13. Huang Y. Inhibitory effect of noradrenaline uptake inhibitors on contractions of rat aortic smooth muscle. Br J Pharmacol. 1996;117(3):5339. doi:10.1111/j.1476-5381.1996.tb15223.x.

14. Rheker J, RiefW, Doering BK, Winkler A. Assessment of adverse events in clinical drug trials: identifying amitriptyline's placebo-and baselinecontrolled side effects. Exp Clin Psychopharmacol. 2018;26(3):320-6. doi:10.1037/pha0000194.
15. Pereira CA, Rodrigues FL, Ruginsk SG, Zanotto CZ, Rodrigues JA, Duarte DA, et al. Chronic treatment with fluoxetine modulates vascular adrenergic responses by inhibition of pre- and post-synaptic mechanisms. Eur J Pharmacol. 2017;800:70-80. doi:10.1016/j. ejphar.2017.02.029.

16. Ungvari Z, Pacher P, Kecskemeti V, Koller A. Fluoxetine dilates isolated small cerebral arteries of rats and attenuates constrictions to serotonin, norepinephrine, and a voltage-dependent Ca (2+) channel opener. Stroke. 1999;30(9):1949-54. doi:10.1161/01.STR.30.9.1949.

17. Freudenmann RW, Freudenmann N, Zurowski B, Schönfeldt-Lecuona C, Maier L, Schmieder RE, et al. [Arterial hyper- and hypotension associated with psychiatric medications: a risk assessment based on the summaries of product characteristics (SmPCs)]. Dtsch Med Wochenschr. 2017;142(16):e100-7. doi:10.1055/s-0043-111739. German.

18. Frieling H, Bleich S. Tranylcypromine: new perspectives on an "old"drug. Eur Arch Psychiatry Clin Neurosci. 2006;256(5):268-73. doi:10.1007/ s00406-006-0660-8.

19. Bujak-Gizycka B, Olszanecki R, Suski M, Madek J, Stachowicz A, Korbut R. Angiotensinogen metabolism in rat aorta: robust formation of proangiotensin-12. J Physiol Pharmacol [Internet]. 2010 [cited 2019 Apr 27];61 (6):679-82. Available from: https://www.ncbi.nlm.nih.gov/ pubmed/21224498.

20. Venlafaxine: more dangerous than most "selective" serotonergic antidepressants. Prescrire Int [Internet]. 2016 [cited 2019 Apr 27];25(170):96-9. Available from: https://www.ncbi.nlm.nih.gov/ pubmed/27186622.

21. Feighner JP. Cardiovascularsafety in depressed patient: Focus on venlafaxine. J Clin Psychiatry [Internet]. 1995 [cited 2019 Apr 27];56(12):574-9. Available from: https://www.ncbi.nlm.nih.gov/ pubmed/8530334.

22. Czubak A, Nowakowska E, Golembiowska K, Kus K, Burda K, Metelska $J$. Effect of venlafaxine and nicotine on the level of neurotransmitters and their metabolites in rat brains. J Physiol Pharmacol [Internet]. 2010 [cited 2019 Apr 27];61(3):339-46. Available from: https://www.ncbi.nlm. nih.gov/pubmed/20610865.

23. Abdelmawla AH, Langley RW, Szabadi E, Bradshaw CM. Comparison of the effects of venlafaxine, desipramine and paroxetine on noradrenalin and methoxamine-evoked constriction of the dorsal hand vein. Br J Clin Pharmacol. 1999;48(3):345-54. doi:10.1046/j.1365-2125.1999.00031.x.

24. Reeve HL, Nelson DP, Archer SL, Weir EK. Effects of fluoxetine, phentermine, and venlafaxine on pulmonary arterial pressure and electrophysiology. Am J Physiol. 1999; 276 (2):L213-9. doi:10.1152/ ajplung.1999.276.2.L213.

25. Stenman M, Holzmann MJ, Sartipy U. Antidepressant use before coronary artery bypass surgery is associated with long-term mortality. Int J Cardiol. 2013;167(6):2958-62. doi:10.1016/j.ijcard.2012.08.010. 